\title{
Transplantation of GABA-Producing Cells for Seizure Control in Models of Temporal Lobe Epilepsy
}

\author{
Kerry Thompson \\ Department of Biology, Occidental College, Los Angeles, California 90041, VA Greater Los Angeles Healthcare System, Los \\ Angeles, California 90012
}

Summary: A high percentage of patients with temporal lobe epilepsy (TLE) are refractory to conventional pharmacotherapy. The progressive neurodegenerative processes associated with a lifetime of uncontrolled seizures mandate the development of alternative approaches to treat this disease. Transplantation of inhibitory cells has been suggested as a potential therapeutic strategy to achieve seizure suppression in humans with intractable TLE. Preclinical investigations over 20 years have demonstrated that multiple cell types from several sources can produce anticonvulsant, and antiepileptogenic, effects in animal models of TLE. Transplanting GABA-producing cells, in particular, has been shown to reduce seizures in several well-established models. This review addresses experimentation using different sources of transplantable GABAergic cells, highlighting progress with fetal tissue, neural cell lines, and stem cells. Regardless of the source of the GABAergic cells used in seizure studies, common challenges have emerged. Several variables influence the anticonvulsant potential of GABA-producing cells. For example, tissue availability, graft survival, immunogenicity, tumorigenicity, and varying levels of cell migration, differentiation, and integration into functional circuits and the microenvironment provided by sclerotic tissue all contribute to the efficacy of transplanted cells. The challenge of understanding how all of these variables work in concert, in a disease process that has no well-established etiology, suggests that there is still much basic research to be done before rational cell-based therapies can be developed for TLE. Key Words: GABA, cell transplantation, temporal lobe epilepsy, seizures, genetic engineering.

\section{INTRODUCTION}

The CNS has a relatively limited capacity for neurogenesis and self-repair. Diseases that are the result of progressive neural losses, such as Alzheimer's and Parkinson's disease, are particularly devastating. The greater the amount of neural tissue loss, the more refractory to pharmacotherapy the patients become, and the greater the negative effects on the quality of life of patients, families, and caregivers.

Cell replacement therapy seems an obvious therapeutic approach for diseases associated with depletion of specific cell populations, and, after decades of promising preclinical research, it was tried clinically on a large scale with fetal grafts for Parkinson's disease. ${ }^{1,2}$ The therapeutic outcomes of the clinical trials were less than expected, however, and were complicated by a number of serious issues, including the emergence of graft-induced adverse effects. ${ }^{3,4}$ Some of the autopsied grafts

Address correspondence and reprint requests to: Kerry Thompson, Department of Biology, Occidental College, 1600 Campus Road, Los Angeles, CA 90041. E-mail: kthompson@oxy.edu. exhibited parkinsonian neuropathology, which suggests that they were affected by the disease process within the host. ${ }^{5,6}$ If transplantation for neurological diseases is to be pursued, consideration of the clinical goals of neural replacement therapy (treating symptoms of the disease or the disease process) and a rational determination of the cases that may benefit from this surgical alternative are warranted.

\section{CELL-BASED THERAPY FOR NEUROLOGICAL DISEASES}

A number of benefits have been reported for cell transplantation in models of clinically intractable diseases such as Parkinson's disease, ${ }^{7}$ Huntington's disease,${ }^{8}$ and temporal lobe epilepsy. ${ }^{9}$ These data demonstrate that this approach may have the potential to serve as a surgical alternative for pharmacoresistant neurological diseases associated with lost or damaged brain tissue..$^{10}$ Even if the underlying cause of a disease is not corrected by neural transplantation, relief of neurological symptoms might improve the quality of life for patients consider- 
ably. In some otherwise refractory cases, symptomatic relief may provide more than simply palliative benefits. For example, in the case of intractable epilepsy, if neural transplantation provided protection from severe chronic seizures, it would protect against the progressive adverse consequences associated with frequent recurrent seizures. ${ }^{11}$ Although there are many forms of epilepsy with a wide range of etiologies, ${ }^{12}$ some cases are thought to be potential targets for cell-based therapy: specifically, the cases that are associated with localized brain damage and that are refractory to pharmacotherapy.

Arguments supporting the exploration of neural transplantation for temporal lobe epilepsy (TLE) are that it is a disease linked to losses in specific cell populations, ${ }^{13}$ a localized pathophysiology, ${ }^{14}$ and pharmacoresistance. ${ }^{12}$ The principal alternative therapy for pharmacoresistant TLE is temporal lobe resection, wherein the epileptic focus (or epileptogenic zone ${ }^{12}$ ) is removed surgically. This approach has a high success rate in terms of seizure relief, ${ }^{15}$ but comes with the cost of a frequent reliance on toxicity-producing antiepileptic drugs, the loss of functioning brain tissue, ${ }^{12}$ and the memory deficits reported in many studies. ${ }^{16-19}$ The TLE patients who have bilaterally originating seizures, or seizures that originate in tissue related to speech, do not qualify for resection and few options exist for these patients. For these reasons, cell-based therapy has been identified as a possible alternative to resection. ${ }^{9,20,21}$

\section{Transplantation in TLE}

Despite relatively meager preclinical data, a small number of humans have received transplants of fetal porcine mesencephalon into epileptic hippocampi, and some benefit was reported. ${ }^{22}$ The trials were suspended because of concerns of potential cross-species virus transfer. This early report of clinical success is promising, but must be viewed with some caution in light of reports of only transient clinical benefit after cerebral transplantation surgery, ${ }^{23}$ and reports of adverse effects produced by fetal transplants in humans with Parkinson's disease. ${ }^{3,4}$ Additionally, preclinical studies have reported epileptogenicity resulting from hippocampal transplants of fetal tissue. ${ }^{24-26}$

The aggressive leap into clinical application illustrates the desperate nature of the search for effective therapies for pharmacoresistant TLE. It also highlights the need for attaining a greater understanding of the potential of cellbased therapies for TLE through rigorous preclinical experimentation, with the concomitant goal of developing safeguards against the potential problems that can arise with this approach.

The consensus view is that the epileptic brain suffers a pathological imbalance of excitation over inhibition. Some research has emphasized the loss of inhibitory cell function in the highly epileptogenic hippocampus and parahippocampal areas. ${ }^{13,27-29}$ The loss of function of key GABA-containing interneurons in the dentate gyrus, for example, may release the excitatory dentate granule cells from GABAergic inhibition and be permissive for seizure expression. ${ }^{30}$ Other studies emphasize the altered circuits that result from the synaptic rearrangement that follows loss of cells in the temporal lobe. ${ }^{31,32}$ Pathological circuits could lead to hypersynchrony, seizure-promoting recurrent excitation, or both.

Other important changes at the genetic level can alter the seizure circuits. For example, gene regulation is perturbed by seizures, ${ }^{33}$ and this leads to ectopic expression of transmitter molecules that could promote seizures. ${ }^{34,35}$

In all cases, the cell replacement strategy would be designed to restore normal levels of inhibition to the seizure-prone area or areas of the brain while sparing the rest of the CNS from potentially toxicity-producing inhibition. This could be achieved simply by raising the inhibitory tone of the epileptogenic zone, without altering the existing circuitry, with a strategically placed bolus of inhibitory cells-providing the cells do not migrate from the site of transplantation. ${ }^{36}$ Alternatively, the goal could be the replacement of lost or dysfunctional inhibitory cells, and the restoration of the circuits that they normally comprise in nonpathological tissues. This could be achieved by transplanting a cell type that can disperse from the injection site and migrate into damaged areas, where the cells would differentiate into GABAergic neurons and integrate into circuits based on the chemical cues of the microenvironment. ${ }^{37}$ An additional objective might be to provide missing targets for axons of excitatory cells (e.g., the mossy fibers of dentate granule cells) to promote rewiring and the undoing of excitatory epileptic circuits. ${ }^{38}$ These different hypotheses have influenced the experimental approach in preclinical studies.

The many considerations involved in the experimental design of transplantation studies for epilepsy include the cell type and tissue source of the grafted cells, the anatomical target within the host (i.e., the seizure focus or a seizure modulating nucleus), the migratory potential of the grafted cells, and the consequences of synaptic integration within the host (which can be prevented by cell containment within a matrix or by the use of cells that do not form synaptic contacts, such as glial cells ${ }^{39,40}$ ). Several recent reviews have described various tissue sources and cell types that have been used in models of TLE. ${ }^{9,21,41}$

Over the last 20 years, several cell types and tissue sources have been evaluated for their potential antiepileptogenic or anticonvulsant effects after transplantation into models of TLE. ${ }^{21}$ For example, fetal tissue rich in cells producing norepinephrine, ${ }^{42,43}$ acetylcholine, ${ }^{44-46}$ or GABA ${ }^{47-49}$ has been shown to retard the development of seizures, primarily in the kindling model of epilepsy. ${ }^{21}$ 
Immortalized neural cell lines (both neuronal and glial) engineered to overexpress glutamate decarboxylase (GAD) and GABA have been shown to suppress seizures in several seizure model. ${ }^{50-54}$

More recently, rodent embryonic stem cells (SCs) that overproduce adenosine ${ }^{36}$ and human embryonic SCs that can differentiate into GABAergic neurons ${ }^{55}$ have been shown to suppress seizures. Some reports indicate that synaptic integration within the host is not required for seizure relief, ${ }^{56}$ and that anticonvulsant effects can be achieved by raising GABA concentrations focally ${ }^{57}$ (at least in the short term), but others stress the need for synaptic integration and brain repair for effective seizure control. ${ }^{20,41}$

\section{GABA-producing cells for TLE}

A number of studies have focused on GABAergic cells as the source of material for transplantation. Cells that produce and release the inhibitory amino acid GABA are a clear choice for transplantation in epilepsy. ${ }^{9,21}$ GABAergic cell losses in brain areas involved in seizure generation or propagation (or both) have been consistently observed in animal models of TLE, ${ }^{58}$ and the loss of GABAergic populations in epileptogenic zones has been confirmed in resected tissue taken from patients with TLE. ${ }^{13}$ Although some debate can legitimately be raised concerning the therapeutic potential of tonically released $\mathrm{GABA}^{59}$ and the altered physiology of GABA receptors in refractory TLE patients ${ }^{60}$, the empirical preclinical evidence suggests that GABAergic cells can provide relief from seizures in well-characterized models of TLE.

\section{Fetal and embryonic tissue transplants}

In the last decade, a number of studies investigating fetal transplantation have advanced the concept that cellbased therapies for TLE are feasible. These studies have demonstrated that both seizure control and, to some degree, circuit repair within damaged temporal lobes can be achieved in models of TLE. Löscher et al. ${ }^{48}$ showed that transient seizure control could be achieved by transplanting GABA-rich fetal tissue into the substantia nigra (SN) using the kindling model of epilepsy. Animals with established seizures had higher afterdischarge thresholds and lower seizure severity scores after transplantation, compared with their pretransplantation measures. No significant changes were seen after control non-GABAergic spinal cord tissue was transplanted. This was a proof-ofprinciple study, showing that GABA-producing cells could modulate experimental seizures when placed in a region that has been shown to serve as a GABA-responsive gate for the expression of seizures. ${ }^{61-63}$

In a 2008 report, striatal tissue containing neural precursor cells was shown to suppress the expression of spontaneous seizures following status epilepticus (SE) when transplanted into the hippocampus bilaterally 4 days after the initial seizure. ${ }^{64}$ After a series of studies that established a graft pretreatment strategy that increases the survival of fetal grafts after transplantation, ${ }^{65}$ this group used the procedure to treat striatum collected from 15-day-old rat embryos containing cells capable of differentiating into GABAergic neurons. These cells were grafted into a rat model of TLE that produces spontaneous seizures. This study was important for a number of reasons. First, it extended the anticonvulsant effect of transplanted cells from days to several weeks (reported in other studies ${ }^{51,53,55}$ ) to several months to 1 year, by pretreatment of the tissue with growth factors and antiapoptotic agents. Second, it demonstrated that, in a model of SE that produces hippocampal and extrahippocampal damage (also seen in clinical cases of TLE ${ }^{66}$ ), transplanting exclusively into the hippocampus could block seizure occurrence. Third, it showed that the therapeutic transplant was predominantly composed of GABAergic neurons.

A series of fetal transplant studies have investigated circuit repair within the hippocampus of animals that have experienced SE. Repair of hippocampal damage produced by the excitotoxin kainate, a pattern of damage that has overlapping features of temporal lobe sclerosis, has been approximated using homotopic fetal transplants, ${ }^{67}$ and these treatments have been shown to reduce epileptogenicity, ${ }^{65}$ possibly by reducing the aberrant mossy fiber growth thought to contribute to chronic seizure development. ${ }^{38,68}$

Axons from dentate granule cells, known as mossy fibers, can sprout into the inner molecular layer of the dentate gyrus, where they can potentially synapse onto granule cell dendrites to create an epileptogenic excitatory loop. A means to diminish mossy fiber sprouting is an important advance, and suggests the possibility that some transplantable cell types may not only increase inhibition by raising GABA levels but may reduce excitatory drive by reconstituting a nonpathological circuit.

Nonetheless, in these reports of circuit repair, the fetal tissue grafts remain as ectopic clusters of cells at the injection site (sometimes infiltrating the ventricles) and do not form consistently reproducible, or recognizable, hippocampal cell layers, and there are limitations related to compatibility between the tissue source and the target region within the host. ${ }^{67}$ Report of seizure induction produced by ectopically placed hippocampal transplants makes this a serious concern. ${ }^{25,69}$ Additionally, poor survival of the transplants is associated with delay of transplantation, relative to the initial injury. ${ }^{70}$

Some of the limitations of hippocampal fetal tissue dispersal and integration within the host hippocampus might be addressed by using a cell source that is less differentiated and that can still respond to migratory cues. Embryonic cells capable of migration and differentiation have a demonstrated capacity to integrate into 
extant cell layers after dispersal, even in the adult. ${ }^{71}$ Rodent embryonic tissue from the lateral ganglionic eminence and medial ganglionic eminence (the source of most cortical interneurons) can disperse into, and align within, both cortical cell layers and hippocampal pyramidal cell layers, and within the hilar region of the dentate gyrus. ${ }^{37}$ These cells differentiate into recognizable and biochemically appropriate interneurons, and can increase GABA-mediated inhibition within the dentate gyrus. To date, these cells have not been used in models of TLE, but it has been suggested. ${ }^{20}$

Despite the advances made with fetal grafting into models of TLE, there remain major limitations to fetal transplants that can compromise experimental design and interpretation. Obligate tissue heterogeneity makes it difficult to assign the therapeutic effect solely to GABAergic cells in these studies, and control tissue typically comes from heterotopic areas of the fetal brain that are presumed to be non-GABAergic. Characterization of the transplanted cells in tissue sections using immunohistochemical techniques narrows the analysis to subpopulations of cells. Interpretations using this methodology are confounded by the fact that undetected cell types could potentially contribute to proconvulsant or anticonvulsant effects. Using transplants in Parkinson's disease patients as an example, the question has been raised of how, and to what extent, contaminating serotonergic cells (recently identified as a major part of the mixed population within transplants evaluated after autopsy) contribute to the long-term therapeutic potential. ${ }^{72}$ Some researchers are pursuing transplantation strategies in models of TLE by genetically engineering transplantable GABA-producing cell lines. This method avoids many of the ethical and practical problems that are associated with the clinical use of fetal tissue, and the approach has been productive when applied to animal models of epilepsy.

\section{Genetically engineered GABA-producing cells}

$\mathrm{We}^{40,52,53,73}$ and other investigators ${ }^{44,48,50,51,56,57,74-77}$ have shown that transplants of genetically modified inhibitory cells can modulate seizures in animal models of TLE. A large number of these studies have used genetically engineered GABA-producing neural cells. The ability to generate self-renewing clonal populations of transplantable GABA-producing cells provides an unlimited cell source and a level of control that has not been available in prior experimentation using cellular transplants for the treatment of seizures.

Cells can be engineered to express either of the two major isoforms of the GABA-synthesizing enzyme, $\mathrm{GAD}_{65}$ and $\mathrm{GAD}_{67}$. Both isoforms have been introduced into immortalized neural populations to produce GABAergic cell lines. ${ }^{78,79}$ There is a dogmatic belief that $\mathrm{GAD}_{65}$ contributes more GABA to the transmitter pool and that $\mathrm{GAD}_{67}$ contributes more GABA to a metabolic pool. This idea is largely driven by the fact that $\mathrm{GAD}_{65}$ is found predominantly in the neuropil and $\mathrm{GAD}_{67}$ is found predominantly in the cell soma ${ }^{80}$, but the reported heterodimerization of the two isoforms ${ }^{81}$ and distribution of $\mathrm{GAD}_{67}$ in $\mathrm{GAD}_{65}$ knockout mice raises questions about this assumption. ${ }^{82}$ Whether GABA is stored in vesicles and released primarily under depolarizing conditions or whether GABA was released tonically or nonsynaptically (or both), from transplanted cells, could have a considerable effect on the ultimate physiological effect of transplanted cells.

The use of clonal GABA-producing cell lines has provided a means to investigate transplant-induced seizuresuppression using a homogeneous population of GABAproducing cells ${ }^{50,51,53,54,83}$ Clonal cell lines have been engineered using two main strategies: 1) GABA-producing neural cells have been immortalized with oncogenes, and these cells have also been additionally engineered with $\mathrm{GAD}_{67}$ to make them GABA-overexpressing cell lines ${ }^{50}$, and 2) non-GABAergic neural cells have been immortalized ${ }^{84}$ and then converted to a GABAergic phenotype by engineering the cells to express $\operatorname{GAD}_{65} .52$ Although the transplantation of cells containing oncogenes (e.g., the SV40 large T oncogene) raises concerns about tumorigenicity, the use of genetically modified ${ }^{85}$ or temperature-sensitive variants of the oncogene ${ }^{52,78}$ (conditional immortalization) has largely avoided the problem of tumor formation.

A major advantage to using clonal, self-renewing GABA producing cell lines, is that they can be well characterized in vitro prior to transplantation. For example, individual cell lines can be compared biochemically and morphologically over many passages under different growth conditions. ${ }^{78}$ The cells can be tested for both basal and evoked release of GABA, and the concentrations of released GABA can be quantified (FIG. 1). In this way, selection of lines with desired release characteristics can be made, based on the experimental aims. Some cell lines have been developed with regulatable promoters driving the GAD enzyme, so that GABA production and release is under tight control (FIG. 1C). If similar strategies were adapted to clinical applications, it would permit individualized treatments and a mechanism to reduce adverse effects related to GABA-overproduction.

GABA-producing cell lines have demonstrated the ability to retard the development of seizures, and block the expression of established seizures in the kindling model of epilepsy. ${ }^{50-52,54,73,83} \mathrm{GAD}_{65}$-engineered mouse cortical neurons and astrocytes, transplanted into the hippocampus ${ }^{54}$ or the anterior $\mathrm{SN}^{52}$, have been shown to be antiepileptogenic with the ability to slow the development of electrical kindling through daily entorhinal cortex stimulation. The cortical neurons, engineered with regulatable GAD, affect hippocampal electrical activity 
A

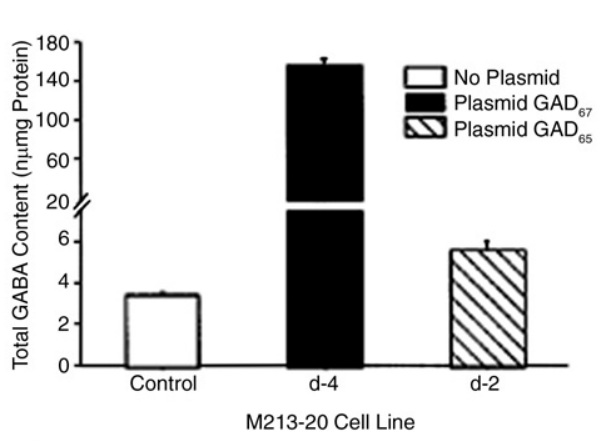

C

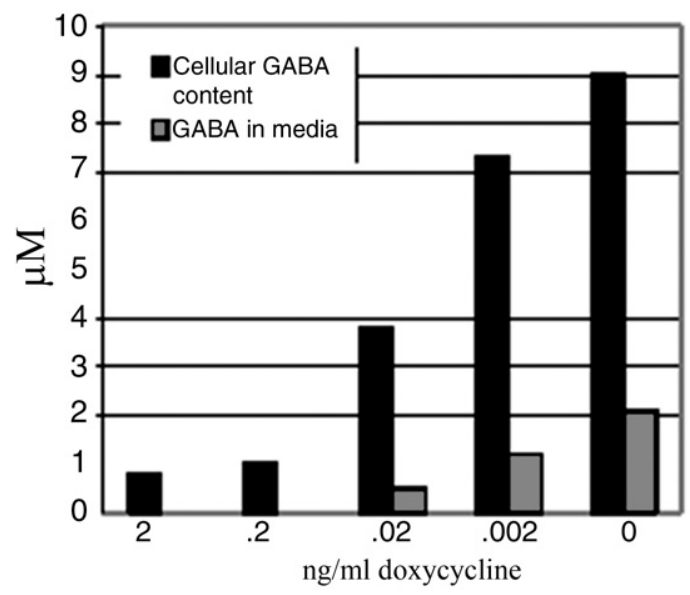

B

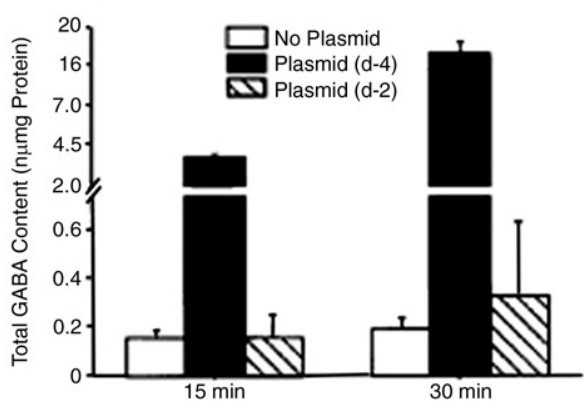

KC1 50 mM (M213-20 Cell Line)

D

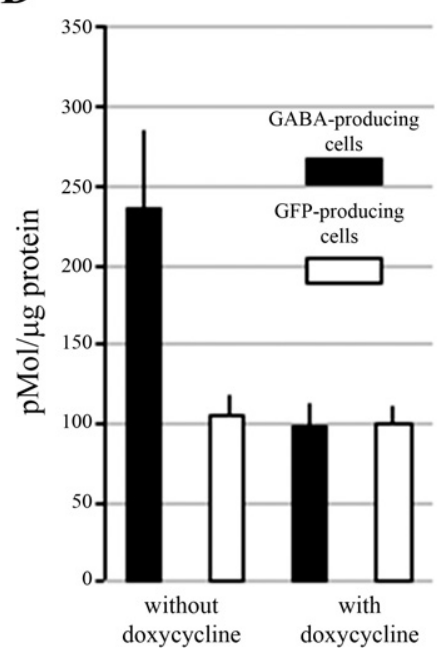

FIG. 1. Characterization of GABA production and release in genetically engineered cell lines, using high performance liquid chromatography. Immortalized rat striatal cells were transfected with human $\mathrm{GAD}_{67}$ and evaluated for total GABA content $(\mathrm{A})$ and depolarization-induced release (B). The characterization of the M213-20 cell line was performed after maintaining the cells in culture for 12-15 months. Immortalized mouse cortical neurons were transfected with rat $\mathrm{GAD}_{65}$ under the control of a tetracycline-regulatable vector. The cells were characterized for GABA content ( $C$, black bars) and release into the media ( $\mathrm{C}$, gray bars) in the presence of doxycycline (a tetracycline derivative) (in $\mathrm{ng} / \mathrm{mL}$ ). Control over the therapeutic transgene can also be achieved in vivo. Animals were transplanted with GABA-producing cells in one hippocampus and green fluorescent protein (GFP)-producing cells in the other. The GABA concentration more than doubled on the side that received GABA-producing cells, but not in the group of animals that received $1 \mathrm{mg} / \mathrm{mL}$ of doxycycline in their drinking water (D). GAD = glutamate decarboxylase; GFP = green fluorescence protein. (Images A and B are reproduced, with permission, from Exp Neurol 2000;161:453-461. ${ }^{78}$ )

after transplantation into the dentate gyrus by raising afterdischarge thresholds and shortening afterdischarge durations. Hippocampal transplants slow kindling in a doxycycline-dependent manner. ${ }^{54}$ Biochemical analysis of hippocampal regions containing the transplanted cells shows that focal tissue elevations in GABA concentration are produced by GAD-engineered cells in the absence, but not in the presence of the controlling agent (Fig. 1D). This is important if the desired goal is to raise inhibition only in an epileptogenic zone, while protecting other regions of the brain from enhanced inhibition.

Striatal cells that are engineered with $\mathrm{GAD}_{67}$ become GABA-overexpressing, and these cells have been evaluated for both antiepileptogenic and anticonvulsant effects in seizure models. Two months after transplantation into the anterior $\mathrm{SN}$, engineered striatal neurons have been shown to raise the amount of systemically delivered kainate necessary to induce seizures, and to suppress the development of generalized seizures. ${ }^{50}$ Anticonvulsant effects of these cells on established, electrically induced seizures has been also been reported after transplantation into the $\mathrm{SN}$, but the effects in that study were shortlived $^{83}$; this study raised important concerns about the potential immunologic response of the epileptic brain to foreign gene products. This is particularly relevant to GAD overproducing cells, because of the known immunogenic properties of this enzyme. ${ }^{86,87}$

GAD-engineered cell lines have been transplanted into the anterior SN of animals that exhibit spontaneous seizures following lithium-pilocarpine (LiPC) -induced, and kainate-induced, SE. In the LiPC study, there was a significant reduction of established spontaneous seizures in animals transplanted with GABA-producing cells, compared with animals transplanted with the parental cells engineered with a reporter molecule, with some animals becoming seizure-free. Notably, the effect was 
reversible; when the animals were given doxycycline in their drinking water, it suppressed transcription of the $\mathrm{GAD}_{65}$ transgene. ${ }^{53}$ Among the beneficial effects of transplantation of GABA-overexpressing cells in this kainate-induced SE study was a reduction of the percentage of animals that experienced severe seizures for as long as 12 weeks after transplantation, and reduced mortality in the animals that received GABA-overexpressing cells. Biochemical evaluation of the transplanted tissue in that study showed that GABA concentrations were elevated in the target tissue for the duration of the experiment. $^{51}$

Cells derived from genetically engineered neural cell lines provide a number of experimental advantages, but they also have limitations that diminish their clinical potential. Besides the concerns of tumorigenicity, and immunogenicity, a major problem has been an inability to sustain long-term effects due to the lack of survival or integration of cells derived from neuronal cell lines in the majority of studies. Limited survival of the transplanted cells has yielded only transient therapeutic effects in most studies-although survival alone may not be the only important determinant of lasting effects, because fetal transplants were reported to provide only transient seizure suppression despite the long-term survival of GABAergic cells. ${ }^{48}$

To date, there is no report of GAD-engineered neuronal cells becoming fully differentiated, and integrated into the seizure circuit of the host; the lack of integration may limit access to trophic factors and thus reduce the survival potential of these cells. Vascular integration is also important and has been addressed only anecdotally. ${ }^{54}$ The transient benefit of engineered cell lines has limited the possibility of investigations with a clinically relevant experimental design. Reviews on this topic have highlighted these limitations. ${ }^{9,21}$ Although recent investigation has sought to address the survival issue by using allografts (rat GABA-producing cell lines into rat brain), that study was complicated by issues seemingly related to the particular epilepsy model and the cell line that was used. ${ }^{83}$ Other survival-promoting strategies, such as pretreating cells with survival factors, ${ }^{88}$ or engineering them with molecules that promote angiogenesis, ${ }^{89,90}$ may be a way to enhance the survival potential and efficacy of genetically engineered GABAproducing cell lines.

The clinical goal would be to transplant cells that produce a sustainable therapeutic effect for the life of the patient. In TLE, the loss of both principal cells and GABAergic interneurons in circuits that are critical for learning and memory justifies the search for transplantable cell types that not only increase GABAergic inhibition, but can, ideally, repopulate multiple cell layers with neurons of the appropriate phenotype and rebuild nonpathological circuits in a predictable manner in scle- rotic tissue. Recent report of a transplant-induced reduction of the supragranular sprouting ${ }^{88}$ and the associated reduced spontaneous seizure occurrence seen in an animal model of SE-induced epilepsy after hippocampal grafting suggests that some approximation of circuit repair can been achieved with hippocampal transplants. As noted, however, reconstitution of normal cytoarchitecture has not been demonstrated in those studies.

An obvious path of exploration for cell-based therapy would be transplantation using a cell type that demonstrated both long-term survival and the capacity to integrate into areas with damaged or lost brain tissue and the ability to repair those sites in a region-specific manner. Ideally, the cells would also have growth characteristics that make possible the development and propagation of clonal cell lines, and the option of genetic engineering, for conditional immortalization or for the introduction of therapeutic genes. Embryonic SCs and neural stem/progenitor cells (NSC) meet these conditions.

Undifferentiated embryonic SCs, ${ }^{91}$ NSC derived from embryonic SCs, and neural progenitor cells ${ }^{92}$ all have the ability to differentiate into neural phenotypes and integrate into the adult brain in a region-specific manner. Stem cells can be engineered in culture to express molecules that drive phenotypic differentiation, ${ }^{93}$ therapeutic molecules, ${ }^{94}$ oncogenes (useful for slow propagating SCs and progenitor cells), ${ }^{95}$ and reporter molecules that permit tracking and identification of SC derivatives in the host brain.

\section{STEM/PROGENITOR CELL TRANSPLANTS}

Although a large number of studies have evaluated the therapeutic potential of SCs and their derivatives in models of neurologic disease, ${ }^{10,75,96}$ research using SCs for transplantation into seizure models is extremely limited. A recent review tabulated just three peer-reviewed studies. ${ }^{41}$ This seems odd, considering that the default differentiation pathway for many rodent and human neural SC lines in culture seems to be GABAergic neurons. ${ }^{97,98}$ In models of traumatic brain injury with hippocampal degeneration, SCs have been reported to migrate into the injured dentate gyrus and differentiate into neurons and glia, ${ }^{99}$ and predifferentiated GABAergic cells derived from embryonic SCs can restore sensorimotor function after traumatic brain injury. ${ }^{100}$ Furthermore, differentiation and integration of SC lines into all hippocampal subfields of the aged brain was associated with improvement in spatial learning, which is thought to be hippocampus dependent. ${ }^{101}$ These data seem to indicate a potential for using SCs to raise hippocampal inhibition and to restore functional circuitry within seizure damaged areas.

The anticipated potential of SCs has not been fully realized in the few published studies in which they have 
been transplanted into seizure models. ${ }^{41}$ Rüschenschmidt et al. ${ }^{102}$ reported that embryonic SC-derived neural precursor cells transplanted into the hippocampi of both naïve animals and animals that had experienced SE could demonstrate neural physiology and develop local circuits. There was no evidence of cell type-specific differentiation within the hippocampus at 1 month after transplantation, nor was there evidence of neural repair.

Some evidence of region-specific migration and differentiation of embryonic SC-derived neural progenitor cells was shown after transplantation into the dentate gyrus of animals that were given the convulsant drug kainate, and then injected with cells within the CA3 region of the hippocampus and the fimbria 7 days later. ${ }^{103}$ After migration into the dentate, most of the cells remained undifferentiated and had markers of immature neuroblasts thought to give rise to granule cells and astrocytes. Prior seizures seemed to protect the immunocompromised animals from the formation of tumors, suggesting a unique microenvironment in the epileptic brain.

When neural SCs, derived from the hippocampi of embryonic mice, were transplanted into the kainate-lesioned rat brain, limited differentiation was seen. Barely more than $50 \%$ of transplanted neurospheres became differentiated cells, and only a small percentage of those cells demonstrated neuronal phenotypes. ${ }^{104}$ The study was performed in aged animals, and the inability of the cells to differentiate into neurons was attributed to the paucity of differentiation and growth factors in the microenvironment of injured, aged brain tissue. Some investigators have argued that the majority of transplant recipients in clinical settings will in fact be older, intractable patients suffering from neurodegenerative processes $^{88}$ and that therefore transplantation studies in aged rats should be explored. ${ }^{101}$

A study by Chu et al. ${ }^{55}$ is notable for reported reduction of recurrent spontaneous seizures, cell dispersion into areas of damage, and enhanced GABAergic inhibition in the damaged hippocampus after transplantation of NSC. In that study, animals experienced 1 hour of continuous seizure induced by LiPC SE. This treatment typically leads to acute cell death in limbic structures, followed later by synaptic reorganization in the dentate gyrus, and the development of the spontaneous seizures. Genetically modified human neural SCs, or saline injections, were introduced into the tail vein of animals at 1 day after they had experienced the hour of generalized seizure. The animals were evaluated visually for behavioral seizures roughly 1 month after the SE. Slice physiology, and histology, were performed roughly 6 weeks after SE. The principal findings were that spontaneous seizure expression was reduced in the SC-injected animals, and that GABAergic inhibition was increased in slice preparations from these animals. Additionally, the tail vein-injected cells selectively infiltrated the damaged limbic structures (primarily the hippocampi and the piriform cortex) with more than $25 \%$ of the cells spontaneously differentiating into GABAergic neurons. A vast majority of cells did not show markers of differentiated neurons. Interestingly, no transplanted cells were found in the brains of animals that received SCs but had not experienced seizures, potentially linking seizures to blood-brain barrier disruptions that would affect cellbased therapies. ${ }^{105}$

We have recently reported a mouse embryonic SC line (ZHTc6) that we genetically engineered with regulatable $\mathrm{GAD}_{65}$ so that the cells and their derivatives overproduce GABA in a controlled manner. ${ }^{106}$ The cells have additional transgenes that produce unique growth characteristics and the $\beta$-galactosidase reporter molecule. ${ }^{107} \mathrm{We}$ have transplanted these cells into animals that have established seizures resulting from LiPC SE. In these animals, we have seen dispersion from the sites of transplantation (four bilateral hippocampal injections) into several brain regions (hippocampal and extrahippocampal). Transplanted cells align within extant cell layers in a reproducible manner, and the cells assume specific phenotypes that are dependent on the location of integration. Integration within the hippocampus occurs preferentially in areas that are heavily damaged by SE and chronic seizures; for example, more cells are found within hippocampal pyramidal cell layers than are found in the dentate granule cell layers (FIGS. 2E and 2F). Animals that do not have hippocampal damage do not show this pattern of integration. The transplantation of these genetically engineered SCs led to seizure suppression (complete in some cases), despite an extended period of chronic epilepsy prior to transplantation $(\sim 18$ months). In some cases, the seizure suppression could be reversed when the controlling agent, doxycycline, was introduced into the drinking water. The combination of seizure suppression and tissue repair in this study is encouraging, but much remains to be done in terms of biochemically characterizing the cells, investigating whether they are electrically active and integrated into functional circuits, and determining the durability of the seizure suppression.

\section{CONCLUSION}

GABA-producing cells can raise inhibition and block seizures in animal models of TLE. Seizure suppression has been demonstrated with a number cell types. Fetal tissue grafts composed predominantly, but not entirely, of GABAergic neurons have a demonstrated ability to block the expression of established seizures and the development of spontaneous seizures when transplanted into seizure-modulating nuclei of the brain. Within the hippocampus, homotopic transplants of fetal tissue have been shown to reduce aberrant axonal sprouting that is 


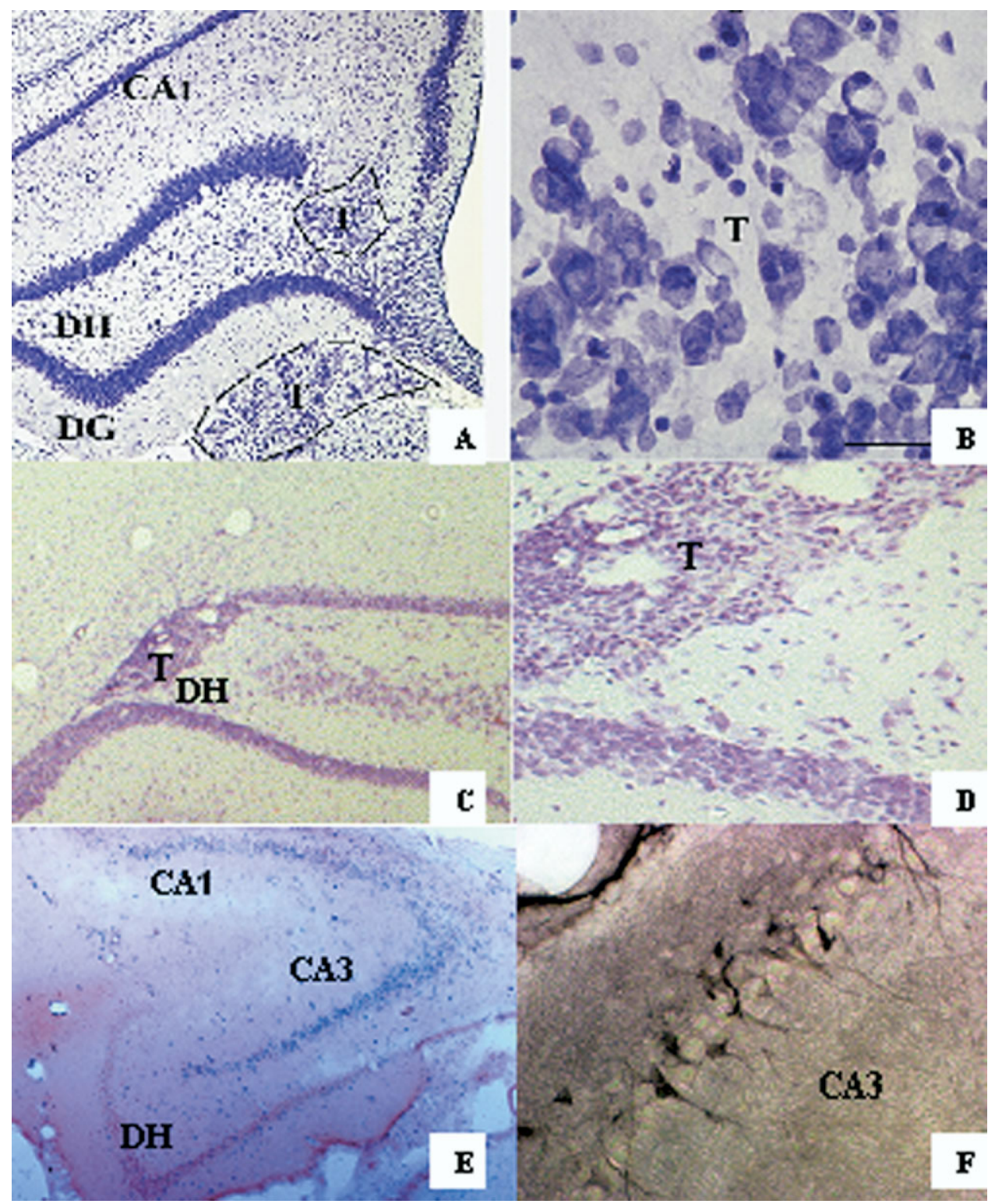

FIG. 2. GABAergic cells from different sources have different growth characteristics in the host hippocampus. (A,B) Nissl-stained sections at low $(A)$ and higher $(B)$ magnification from an animal that underwent SE and received GABAergic fetal grafts show clusters of cells surrounding hippocampal cell layers. These transplants can reduce aberrant mossy fiber sprouting, but there is little restoration of normal cytoarchitecture. (C,D) Nissl-stained sections at low (C) and higher (D) magnification from a kindled animal that was transplanted with conditionally immortalized mouse cortical neurons engineered to produce GABA shows the cells existing within the host as a highly circumscribed bolus, which is typical of this cell type. (E,F) Stem cells that were genetically engineered with both a reporter molecule and $\mathrm{GAD}_{65}$ under the control of a tet-off promoter were transplanted into an animal that experienced SE induced by pilocarpine after lithium pretreatment. The cells migrated to, aligned within, and reconstituted the damaged pyramidal cell layer. (E) Histochemical stain with blue $\beta$-galactosidase reaction product in transplanted cells; the cells differentiated into cell layer appropriate phenotypes. (F) Immunohistochemical stain with antibody directed against $\beta$-galactosidase. $C A 1$ and $C A 3=$ pyramidal cell layers; $D G=$ dentate granule cells; $\mathrm{DH}=$ dentate hilar region; $\mathrm{T}$ = transplant core. (Images A and B are reproduced, with permission, fom Exp Neurol 2008;212:468-481.64)

potentially epileptogenic, ${ }^{88}$ but these grafts seldom align along endogenous cell layers or demonstrate recognizable cytoarchitecture, so the question of whether the grafts produce functional circuits is still open. Embryonic GABA neuron precursors from the medial ganglionic eminence seem to respond to local cues and insert themselves into extant hippocampal cell layers more readily, and it will be worth investigating to see if these cells can suppress seizures. ${ }^{20}$

Immortalized neural cell lines that produce GAD and GABA have the advantage of being a homogeneous, self-renewing population of GABAergic cells, and the use of cell lines overcomes some of the practical and ethical limitations of using fetal tissue. Genetically en- 
gineering transplantable cells to produce GABA provides a number of advantages, including control over the amount of GABA that is produced and released from the cells. There is little evidence, however, of dispersion or integration within the host after transplantation of genetically modified GABA-producing cell transplants. Even though this cell type can suppress many types of experimental seizures, ${ }^{50-54,83}$ including spontaneous seizures, the ability of these cells to restore functional circuitry is questionable. The lack of synaptic integration of these cells likely reduces access to trophic factors and vascularization by the host, leading, generally, to short-term survival and short-term benefit.

Recent studies have shown that transplantation of embryonic SCs, and embryonic SC-derived neural stem/progenitor cells can disperse and integrate into the damaged hippocampus and restore function. ${ }^{99,101}$ Transplantation of human NSC is associated with cell dispersion into damaged areas of the limbic system, increased hippocampal inhibition, and reduction of spontaneous seizures. Many questions remain to be answered about the ability of SCs to completely differentiate within the host, and to differentiate into region-specific phenotypes rather than glial cells in sclerotic hippocampi, ${ }^{108}$ and the long-term integration and survival capacity in the seizure-prone brain of these cells is unknown.

Further development of immortalized GABA-producing lines ${ }^{109}$ and neural stem cell/progenitor cell lines that can differentiate into GABAergic cells and principal cells is reasonable. Experiments are needed that are designed to understand the survival potential of transplanted cells, the site-specific integration and electrophysiological properties of the cells, and the ability to suppress seizures on the scale of months to years. The continued development of transplantation strategies with GABA-producing cells may eventually lead to a useful therapeutic alternative for intractable temporal lobe epilepsy.

\section{REFERENCES}

1. Olanow CW, Goetz CG, Kordower JH, et al. A double-blind controlled trial of bilateral fetal nigral transplantation in Parkinson's disease. Ann Neurol 2003;54:403-414.

2. Freed CR, Greene PE, Breeze RE, et al. Transplantation of embryonic dopamine neurons for severe Parkinson's disease. N Engl J Med 2001;344:710-719.

3. Hagell P, Piccini P, Björklund A, et al. Dyskinesias following neural transplantation in Parkinson's disease. Nat Neurosci 2002; 5:627-628.

4. Ma Y, Feigin A, Dhawan V, et al. Dyskinesia after fetal cell transplantation for parkinsonism: a PET study. Ann Neurol 2002; 52:628-634.

5. Li JY, Englund E, Holton JL, et al. Lewy bodies in grafted neurons in subjects with Parkinson's disease suggest host-to-graft disease propagation. Nat Med 2008;14:501-503.

6. Kordower JH, Chu Y, Hauser RA, Freeman TB, Olanow CW. Lewy body-like pathology in long-term embryonic nigral transplants in Parkinson's disease. Nat Med 2008;14:504-506.
7. Newman MB, Bakay RA. Therapeutic potentials of human embryonic stem cells in Parkinson's disease. Neurotherapeutics 2008;5:237-251.

8. Clelland CD, Barker RA, Watts C. Cell therapy in Huntington disease. Neurosurg Focus 2008;24(3-4):E9.

9. Raedt R, Van Dycke A, Vonck K, Boon P. Cell therapy in models for temporal lobe epilepsy. Seizure 2007;16:565-578.

10. Kim SU. Genetically engineered human neural stem cells for brain repair in neurological diseases. Brain Dev 2007;29:193201.

11. Pitkänen A, Sutula TP. Is epilepsy a progressive disorder? Prospects for new therapeutic approaches in temporal-lobe epilepsy. Lancet Neurol 2002;1:173-181.

12. Engel J Jr. Seizures and epilepsy. Philadelphia: F.A. Davis Company, 1989.

13. de Lanerolle NC, Kim JH, Robbins RJ, Spencer DD. Hippocampal interneuron loss and plasticity in human temporal lobe epilepsy. Brain Res 1989;495:387-395.

14. Parent JM, Lowenstein DH. Mossy fiber reorganization in the epileptic hippocampus. Curr Opin Neurol 1997;10:103-109.

15. Ryvlin P. Beyond pharmacotherapy: surgical management. Epilepsia 2003;44 Suppl 5:23-28.

16. Gleissner U, Sassen R, Lendt M, Clusmann H, Elger CE, Helmstaedter C. Pre- and postoperative verbal memory in pediatric patients with temporal lobe epilepsy. Epilepsy Res 2002;51:287296.

17. Martin RC, Kretzmer T, Palmer C, et al. Risk to verbal memory following anterior temporal lobectomy in patients with severe left-sided hippocampal sclerosis. Arch Neurol 2002;59:18951901.

18. Rausch R. Epilepsy surgery within the temporal lobe and its short-term and long-term effects on memory. Curr Opin Neurol 2002;15:185-189.

19. Pillon B, Bazin B, Deweer B, Ehrlé N, Baulac M, Dubois B. Specificity of memory deficits after right or left temporal lobectomy. Cortex 1999;35:561-571.

20. Richardson RM, Barbaro NM, Alvarez-Buylla A, Baraban SC. Developing cell transplantation for temporal lobe epilepsy. Neurosurg Focus 2008;24(3-4):E17.

21. Löscher W, Gernert M, Heinemann U. Cell and gene therapies in epilepsy: promising avenues or blind alleys? Trends Neurosci 2008;31:62-73.

22. Edge AS. Current applications of cellular xenografts. Transplant Proc 2000;32:1169-1171.

23. Rosenfeld JV. Current issues in neural transplantation. Ann Acad Med Singapore 1993;22(3 Suppl):464-469.

24. Buzsáki G, Freund T, Björklund A, Gage FH. Restoration and deterioration of function by brain grafts in the septohippocampal system. Prog Brain Res 1988;78:69-77.

25. Buzsáki G, Bayardo F, Miles R, Wong RK, Gage FH. The grafted hippocampus: an epileptic focus. Exp Neurol 1989;105:10-22.

26. Ogawa Y, Sawamoto K, Miyata T, et al. Transplantation of in vitro-expanded fetal neural progenitor cells results in neurogenesis and functional recovery after spinal cord contusion injury in adult rats. J Neurosci Res 2002;69:925-933.

27. Sloviter RS. Permanently altered hippocampal structure, excitability, and inhibition after experimental status epilepticus in the rat: the "dormant basket cell" hypothesis and its possible relevance to temporal lobe epilepsy. Hippocampus 1991;1:41-66.

28. Babb T. Research on the anatomy and pathology of epileptic tissue. In: Lüders H, editor. Epilepsy surgery. 1st ed. New York: Raven Press, 1991:719-727.

29. Thompson K, Holm AM, Schousboe A, Popper P, Micevych P, Wasterlain C. Hippocampal stimulation produces neuronal death in the immature brain. Neuroscience 1998;82:337-348.

30. Sloviter RS, Zappone CA, Harvey BD, Bumanglag AV, Bender RA, Frotscher M. "Dormant basket cell" hypothesis revisited: relative vulnerabilities of dentate gyrus mossy cells and inhibitory interneurons after hippocampal status epilepticus in the rat. J Comp Neurol 2003;459:44-76.

31. Buckmaster PS, Zhang GF, Yamawaki R. Axon sprouting in a model of temporal lobe epilepsy creates a predominantly excitatory feedback circuit. J Neurosci 2002;22:6650-6658. 
32. Sutula TP, Dudek FE. Unmasking recurrent excitation generated by mossy fiber sprouting in the epileptic dentate gyrus: an emergent property of a complex system. Prog Brain Res 2007;163: 541-563.

33. Lowenstein DH. Recent advances related to basic mechanisms of epileptogenesis. Epilepsy Res Suppl 1996;11:45-60.

34. Schwarzer C, Williamson JM, Lothman EW, Vezzani A, Sperk G. Somatostatin, neuropeptide Y, neurokinin B and cholecystokinin immunoreactivity in two chronic models of temporal lobe epilepsy. Neuroscience 1995;69:831-845.

35. Vezzani A, Sperk G. Overexpression of NPY and Y2 receptors in epileptic brain tissue: an endogenous neuroprotective mechanism in temporal lobe epilepsy? Neuropeptides 2004;38:245-252.

36. Boison D. Adenosine-based cell therapy approaches for pharmacoresistant epilepsies. Neurodegener Dis 2007;4:28-33.

37. Alvarez-Dolado M, Calcagnotto ME, Karkar KM, et al. Cortical inhibition modified by embryonic neural precursors grafted into the postnatal brain. J Neurosci 2006;26:7380-7389.

38. Shetty AK, Zaman V, Hattiangady B. Repair of the injured adult hippocampus through graft-mediated modulation of the plasticity of the dentate gyrus in a rat model of temporal lobe epilepsy. J Neurosci 2005;25:8391-8401.

39. New KC, Rabkin SD. GABA synthesis in astrocytes after infection with defective herpes simplex virus vectors expressing glutamic acid decarboxylase 65 or 67. J Neurochem 1998;71:23042312.

40. Behrstock SP, Anantharam V, Thompson KW, Schweitzer ES, Tobin AJ. Conditionally-immortalized astrocytic cell line expresses GAD and secretes GABA under tetracycline regulation. J Neurosci Res 2000;60:302-310.

41. Shetty AK, Hattiangady B. Concise review: prospects of stem cell therapy for temporal lobe epilepsy. Stem Cells 2007;25:23962407.

42. Barry DI, Kikvadze I, Brundin P, Bolwig TG, Björklund A, Lindvall O. Grafted noradrenergic neurons suppress seizure development in kindling-induced epilepsy. Proc Natl Acad Sci U S A 1987;84:8712-8715.

43. Barry DI, Wanscher B, Kragh J, et al. Grafts of fetal locus coeruleus neurons in rat amygdala-piriform cortex suppress seizure development in hippocampal kindling. Exp Neurol 1989; 106:125-132.

44. Ferencz I, Kokaia M, Elmér E, Keep M, Kokaia Z, Lindvall O. Suppression of kindling epileptogenesis in rats by intrahippocampal cholinergic grafts. Eur J Neurosci 1998;10:213-220.

45. Ferencz I, Leanza G, Nanobashvili A, Kokaia M, Lindvall O. Basal forebrain neurons suppress amygdala kindling via cortical but not hippocampal cholinergic projections in rats. Eur J Neurosci 2000;12:2107-2116.

46. Ferencz I, Leanza G, Nanobashvili A, Kokaia Z, Kokaia M, Lindvall O. Septal cholinergic neurons suppress seizure development in hippocampal kindling in rats: comparison with noradrenergic neurons. Neuroscience 2001;102:819-832.

47. Fine A, Meldrum BS, Patel S. Modulation of experimentally induced epilepsy by intracerebral grafts of fetal GABAergic neurons. Neuropsychologia 1990;28:627-634.

48. Löscher W, Ebert U, Lehmann H, Rosenthal C, Nikkhah G. Seizure suppression in kindling epilepsy by grafts of fetal GABAergic neurons in rat substantia nigra. J Neurosci Res 1998; 51:196-209.

49. Stevens JR, Phillips I, Freed WJ, Poltorak M. Cerebral transplants for seizures: preliminary results. Epilepsia 1988;29:731-737.

50. Castillo CG, Mendoza S, Freed WJ, Giordano M. Intranigral transplants of immortalized GABAergic cells decrease the expression of kainic acid-induced seizures in the rat. Behav Brain Res 2006;171:109-115.

51. Castillo CG, Mendoza-Trejo S, Aguilar MB, Freed WJ, Giordano M. Intranigral transplants of a GABAergic cell line produce longterm alleviation of established motor seizures. Behav Brain Res 2008;193:17-27.

52. Thompson K, Anantharam V, Behrstock S, Bongarzone E, Campagnoni A, Tobin AJ. Conditionally immortalized cell lines, engineered to produce and release GABA, modulate the development of behavioral seizures. Exp Neurol 2000;161:481-489.
53. Thompson KW, Suchomelova LM. Transplants of cells engineered to produce GABA suppress spontaneous seizures. Epilepsia 2004;45:4-12.

54. Thompson KW. Genetically engineered cells with regulatable GABA production can affect afterdischarges and behavioral seizures after transplantation into the dentate gyrus. Neuroscience 2005; 133:1029-1037.

55. Chu K, Kim M, Jung KH, et al. Human neural stem cell transplantation reduces spontaneous recurrent seizures following pilocarpine-induced status epilepticus in adult rats. Brain Res 2004; 1023:213-221.

56. Boison D, Huber A, Padrun V, Déglon N, Aebischer P, Möhler H Seizure suppression by adenosine-releasing cells is independent of seizure frequency. Epilepsia 2002;43:788-796.

57. Kokaia M, Aebischer P, Elmér E, et al. Seizure suppression in kindling epilepsy by intracerebral implants of GABA- but not by noradrenaline-releasing polymer matrices. Exp Brain Res 1994; 100:385-394

58. Dudek FE, Sutula TP. Epileptogenesis in the dentate gyrus: a critical perspective. Prog Brain Res 2007;163:755-773.

59. Leidenheimer NJ. Regulation of excitation by $\mathrm{GABA}_{\mathrm{A}}$ receptor internalization. Results Probl Cell Differ 2008;44:1-28.

60. Ragozzino D, Palma E, Di Angelantonio S, et al. Rundown of GABA type A receptors is a dysfunction associated with human drug-resistant mesial temporal lobe epilepsy. Proc Natl Acad Sci U S A 2005;102:15219-15223.

61. Gale K. Progression and generalization of seizure discharge: anatomical and neurochemical substrates. Epilepsia 1988;29 Suppl 2:S15-S34.

62. Gale K. Role of the substantia nigra in GABA-mediated anticonvulsant actions. Adv Neurol 1986;44:343-364.

63. McNamara JO, Rigsbee LC, Galloway MT. Evidence that substantia nigra is crucial to neural network of kindled seizures. Eur J Pharmacol 1983;86:485-486.

64. Hattiangady B, Rao MS, Shetty AK. Grafting of striatal precursor cells into hippocampus shortly after status epilepticus restrains chronic temporal lobe epilepsy. Exp Neurol 2008;212:468-481.

65. Rao MS, Hattiangady B, Rai KS, Shetty AK. Strategies for promoting anti-seizure effects of hippocampal fetal cells grafted into the hippocampus of rats exhibiting chronic temporal lobe epilepsy. Neurobiol Dis 2007;27:117-132.

66. Moran NF, Lemieux L, Kitchen ND, Fish DR, Shorvon SD Extrahippocampal temporal lobe atrophy in temporal lobe epilepsy and mesial temporal sclerosis. Brain 2001;124:167-175.

67. Shetty AK, Zaman V, Turner DA. Pattern of long-distance projections from fetal hippocampal field CA3 and CA1 cell grafts in lesioned CA3 of adult hippocampus follows intrinsic character of respective donor cells. Neuroscience 2000;99:243-255.

68. Shetty AK, Turner DA. Fetal hippocampal grafts containing CA3 cells restore host hippocampal glutamate decarboxylase-positive interneuron numbers in a rat model of temporal lobe epilepsy. J Neurosci 2000;20:8788-8801.

69. Buzsáki G, Masliah E, Chen LS, Horváth Z, Terry R, Gage FH. Hippocampal grafts into the intact brain induce epileptic patterns. Brain Res 1991;554:30-37.

70. Zaman V, Shetty AK. Survival of fetal hippocampal CA3 cell grafts in the middle-aged and aged hippocampus: effect of host age and deafferentation. J Neurosci Res 2002;70:190-199.

71. Wichterle H, Garcia-Verdugo JM, Herrera DG, Alvarez-Buylla A. Young neurons from medial ganglionic eminence disperse in adult and embryonic brain. Nat Neurosci 1999;2:461-466.

72. Braak H, Del Tredici K. Assessing fetal nerve cell grafts in Parkinson's disease. Nat Med 2008;14:483-485.

73. Gernert M, Thompson KW, Löscher W, Tobin AJ. Genetically engineered GABA-producing cells demonstrate anticonvulsant effects and long-term transgene expression when transplanted into the central piriform cortex of rats. Exp Neurol 2002;176: 183-192.

74. Löscher W, Ebert U, Lehmann H, Rosenthal C, Nikkhah G. Seizure suppression in kindling epilepsy by grafts of fetal GABAergic neurons in rat substantia nigra. J Neurosci Res 1998; 51:196-209. 
75. Björklund A, Lindvall O. Cell replacement therapies for central nervous system disorders. Nat Neurosci 2000;3:537-544.

76. Huber A, Padrun V, Déglon N, Aebischer P, Möhler H, Boison D. Grafts of adenosine-releasing cells suppress seizures in kindling epilepsy. Proc Natl Acad Sci U S A 2001;98:7611-7616.

77. Bengzon J, Kokaia M, Brundin P, Lindvall O. Seizure suppression in kindling epilepsy by intrahippocampal locus coeruleus grafts: evidence for an alpha-2-adrenoreceptor mediated mechanism. Exp Brain Res 1990;81:433-437.

78. Conejero-Goldberg C, Tornatore C, Abi-Saab W, et al. Transduction of human $\mathrm{GAD}_{67}$ cDNA into immortalized striatal cell lines using an Epstein-Barr virus-based plasmid vector increases GABA content. Exp Neurol 2000;161:453-461.

79. Thompson K, Guttman O, Tobin AJ. Doxycycline-dependent modulation of kindled seizures following hippocampal transplantation of cells engineered to produce GABA. Abstr Soc Neurosci 1999;25:846.

80. Soghomonian JJ, Martin DL. Two isoforms of glutamate decarboxylase: why? Trends Pharmacol Sci 1998;19:500-505.

81. Dirkx R Jr, Thomas A, Li L, et al. Targeting of the $67-\mathrm{kDa}$ isoform of glutamic acid decarboxylase to intracellular organelles is mediated by its interaction with the $\mathrm{NH}_{2}$-terminal region of the $65-\mathrm{kDa}$ isoform of glutamic acid decarboxylase. J Biol Chem 1995;270:2241-2246.

82. Kanaani J, Lissin D, Kash SF, Baekkeskov S. The hydrophilic isoform of glutamate decarboxylase, $\mathrm{GAD}_{67}$, is targeted to membranes and nerve terminals independent of dimerization with the hydrophobic membrane-anchored isoform, $\mathrm{GAD}_{65}$. J Biol Chem 1999;274:37200-37209.

83. Nolte MW, Löscher W, Herden C, Freed WJ, Gernert M. Benefits and risks of intranigral transplantation of GABA-producing cells subsequent to the establishment of kindling-induced seizures. Neurobiol Dis 2008;31:342-354.

84. Bongarzone ER, Foster LM, Byravan S, et al. Conditionally immortalized neural cell lines: potential models for the study of neural cell function. Methods 1996;10:489-500.

85. Truckenmiller ME, Tornatore C, Wright RD, et al. A truncated SV40 large $\mathrm{T}$ antigen lacking the p53 binding domain overcomes p53-induced growth arrest and immortalizes primary mesencephalic cells. Cell Tissue Res 1998;291:175-189.

86. Tuomi T, Groop LC, Zimmet PZ, Rowley MJ, Knowles W, Mackay IR. Antibodies to glutamic acid decarboxylase reveal latent autoimmune diabetes mellitus in adults with a non-insulindependent onset of disease. Diabetes 1993;42:359-362.

87. De Aizpurua HJ, Wilson YM, Harrison LC. Glutamic acid decarboxylase autoantibodies in preclinical insulin-dependent diabetes. Proc Natl Acad Sci U S A 1992;89:9841-9845.

88. Rao MS, Hattiangady B, Shetty AK. Fetal hippocampal CA3 cell grafts enriched with FGF-2 and BDNF exhibit robust long-term survival and integration and suppress aberrant mossy fiber sprouting in the injured middle-aged hippocampus. Neurobiol Dis 2006; 21:276-290

89. Carlson BB, Behrstock S, Tobin AJ, Salamone JD. Brain implantations of engineered GABA-releasing cells suppress tremor in an animal model of Parkinsonism. Neuroscience 2003;119:927-932.

90. Silverman WF, Krum JM, Mani N, Rosenstein JM. Vascular, glial and neuronal effects of vascular endothelial growth factor in mesencephalic explant cultures. Neuroscience 1999;90:15291541.

91. Harkany T, Andäng M, Kingma HJ, et al. Region-specific generation of functional neurons from naive embryonic stem cells in adult brain. J Neurochem 2004;88:1229-1239.
92. Englund U, Björklund A, Wictorin K. Migration patterns and phenotypic differentiation of long-term expanded human neural progenitor cells after transplantation into the adult rat brain. Brain Res Dev Brain Res 2002;134:123-141.

93. Arenas E. Engineering a dopaminergic phenotype in stem/precursor cells: role of Nurr1, glia-derived signals, and Wnts. Ann N Y Acad Sci 2005;1049:51-66.

94. Rooney GE, Moran C, McMahon SS, et al. Gene-modified mesenchymal stem cells express functionally active nerve growth factor on an engineered poly lactic glycolic acid (PLGA) substrate. Tissue Eng Part A 2008;14:681-690.

95. De Filippis L, Ferrari D, Rota Nodari L, Amati B, Snyder E, Vescovi AL. Immortalization of human neural stem cells with the c-myc mutant T58A. PLoS ONE 2008;3:e3310.

96. Shihabuddin LS, Palmer TD, Gage FH. The search for neural progenitor cells: prospects for the therapy of neurodegenerative disease. Mol Med Today 1999;5:474-480.

97. Westmoreland JJ, Hancock CR, Condie BG. Neuronal development of embryonic stem cells: a model of GABAergic neuron differentiation. Biochem Biophys Res Commun 2001;284:674-680.

98. Jain M, Armstrong RJ, Tyers P, Barker RA, Rosser AE. GABAergic immunoreactivity is predominant in neurons derived from expanded human neural precursor cells in vitro. Exp Neurol 2003;182:113-123.

99. Maegele M, Schaefer U. Stem cell-based cellular replacement strategies following traumatic brain injury (TBI). Minim Invasive Ther Allied Technol 2008;17:119-131.

100. Becerra GD, Tatko LM, Pak ES, Murashov AK, Hoane MR. Transplantation of GABAergic neurons but not astrocytes induces recovery of sensorimotor function in the traumatically injured brain. Behav Brain Res 2007;179:118-125.

101. Hodges H, Veizovic T, Bray N, et al. Conditionally immortal neuroepithelial stem cell grafts reverse age-associated memory impairments in rats. Neuroscience 2000;101:945-955.

102. Rüschenschmidt C, Koch PG, Brüstle $\mathrm{O}$, Beck H. Functional properties of ES cell-derived neurons engrafted into the hippocampus of adult normal and chronically epileptic rats. Epilepsia 2005;46 Suppl 5:174-183.

103. Carpentino JE, Hartman NW, Grabel LB, Naegele JR. Regionspecific differentiation of embryonic stem cell-derived neural progenitor transplants into the adult mouse hippocampus following seizures. J Neurosci Res 2008;86:512-524.

104. Shetty AK, Rao MS, Hattiangady B. Behavior of hippocampal stem/progenitor cells following grafting into the injured aged hippocampus. J Neurosci Res 2008:3062-3074.

105. van Vliet EA, da Costa Araújo S, Redeker S, van Schaik R, Aronica E, Gorter JA. Blood-brain barrier leakage may lead to progression of temporal lobe epilepsy. Brain 2007;130:521-534.

106. Thompson K, Hobbs E, Tachibana F, Geraets D. Embryonic stem cells genetically engineered to over-express GABA. Abstract P-68, 12th International Symposium on Neural Regeneration. Neurorehabil Neural Repair 2007;21:609.

107. Niwa H, Miyazaki J, Smith AG. Quantitative expression of Oct3/4 defines differentiation, dedifferentiation or self-renewal of ES cells. Nat Genet 2000;24:372-376.

108. Seidenfaden R, Desoeuvre A, Bosio A, Virard I, Cremer H. Glial conversion of SVZ-derived committed neuronal precursors after ectopic grafting into the adult brain. Mol Cell Neurosci 2006;32: 187-198.

109. Sanchez JF, Crooks DR, Lee CT, et al. GABAergic lineage differentiation of AF5 neural progenitor cells in vitro. Cell Tissue Res 2006;324:1-8. 